\title{
Prevalence and Risk Factors of Malaria in HIV-Infected Pregnant Women on Anti-Retroviral Therapy in Enugu, South East Nigeria
}

Ogboi Sonny JohnbulI ${ }^{\star}$, Agu P Uche ${ }^{2}$, Akpoigbe $\mathrm{J} \mathrm{Kesiena}^{3}$, Fagbamigbe A Francis ${ }^{4}$, Audu Oyemocho ${ }^{5}$, Obianwu IM ${ }^{4}$ and Akabueze $\mathrm{J}^{2}$

${ }^{1}$ Malaria and Human Development, Dept of Life Sciences \& Public Health, University of Camerino, 62032 Camerino (MC), Italy

${ }^{2}$ Department of Obstetrics and Gynaecology, University of Nigeria Teaching Hospital, Ituku-Ozalla, Enugu, Nigeria

${ }^{3}$ Society for Family Health, Garki Abuja, Nigeria

${ }^{4}$ Depeartment of Epidemiology and Medical Statistics, University of Ibadan, Nigeria

${ }^{5}$ Benue State University Makurdi, Nigeria

\begin{abstract}
Background and objective: Malaria and HIV co-infection pose significant health concerns in many regions of the world. Co-infection significantly increases the burden of these diseases in pregnancy, yet the interactions of these diseases in pregnant women are not well understood. The aim of the study was to determine the prevalence and examine the factors that could be associated with malaria in HIV positive infected pregnant women on antiretroviral therapy.
\end{abstract}

Methodology: Blood samples were collected from 301 confirmed HIV positive pregnant women in various trimesters and examined for malaria parasite presence and density with other laboratory indices. Baseline socio-demographic information, antenatal information, CD4 levels, and viral load were collected from clinical records. Information on type of treatment, such as intermittent malaria preventive treatment (IPT) and ART therapy/ prophylaxis, was extracted from care cards. Information on the prior use of antimalarial drugs and cotrimoxazole intake was obtained from direct interviews.

Results: The prevalence of malaria among HIV-positive pregnant women was $49.83 \%$ and the odds of having malaria doubled with living in a rural community (AOR 2.04, $\mathrm{Cl}[1.07-3.91] \mathrm{P}<0.001$ ). Also, being on ART therapy increased the odds of having malaria by $133 \%$ (AOR $2.33 \mathrm{Cl}[1.06-5.10] \mathrm{P}<0.05)$. A higher level of $\mathrm{CD} 4$ counts reduced the odds of malaria parasitaemia though not significant. Those whose CD4 count was 200-350 and $>350$ had reduced odds of malaria parasitaemia (AOR 0.50, $\mathrm{Cl}[0.81-1.44] \mathrm{P}=0.202$ ) and (AOR 0.65, $\mathrm{Cl}[0.24-1.73] \mathrm{P}=0.391$ ), respectively, compared with those with lower CD4 counts. Malaria parasites were unlikely in those with normal haemoglobin levels (AOR $0.08 \mathrm{Cl}[0.04-0.16] \mathrm{P}<0.001$ ). Pregnant women who were not on treatment before coming to the hospital ANC were about nine times more likely to have malaria parasites than those who had it recently (AOR 9.30, CI [4.44-19.50] $\mathrm{P}<0.001)$

Conclusion: The prevalence of malaria in HIV-positive pregnant women was influenced by the locality, level of haemoglobin and self-medication prior to coming to the hospital. Low haemoglobin, which serves as an index of malnutrition, was also a serious factor that should be evaluated to reduce the scourge and burden of malaria complications, and programs geared towards provision of mosquito and environmental barriers should be improved.

Keywords: Rural HIV; ART therapy; CD4; Enugu, Nigeria

\section{Introduction}

Malaria and HIV are among the principal causes of morbidity and mortality in resource-limited settings including sub-Saharan Africa [1]. Despite the international community's efforts to reduce the incidence and prevalence of these diseases, they remain serious health problems in tropical and sub-tropical regions throughout the world [1]. According to the World Malaria Report 2011, there were 225 million cases of malaria and an estimated 781,000 deaths in 2010 [2]. It is estimated that each year, about 24 million pregnant women are affected by Plasmodium falciparum, especially in sub-Saharan Africa [3], and about 1 million per year are co-infected with HIV [4]. Together, malaria and HIV infection cause more than 4 million deaths per year $[5,6]$.

The interactions of malaria parasites and HIV are serious health challengesas it causes complications including severity of clinical signs and other symptoms [7]. Presentation of malaria in HIV-infected people is severe than non-infected individuals [8]. In a review of HIV-1 infection in Africa, malaria was identified as the third cause of HIV-related morbidity [9]. This is more evident in special populations such as HIV-infected pregnant women [3]. Pregnant women living in malaria-endemic regions, particularly in sub-Saharan Africa, have a high frequency and density of Plasmodium falciparum parasitaemia.
There are high rates of maternal morbidity including fever, severe anaemia, abortion, still birth, and placental malaria among these women.Consequently, babies can be born with low birth weight due to both prematurity and intrauterine growth retardation $[3,10]$. However, epidemiological studies of the prevalence and clinical manifestations of P. Falciparum malaria in HIV-infected pregnant women that consider factors such as residential location, CD4 level, viral load, and adherence to intermittent preventive treatment (IPT) and cotrimoxazole regimen, are limited.

Nigeria has one of the highest malaria burdens in the world. In 2010,

*Corresponding author: Ogboi Sonny Johnbull, Malaria and Human Development, Dept of Life Sciences and Public Health, University of Camerino, 62032 Camerino (MC), Italy, Tel: +393806975057; E-mail: ogboijb@yahoo.com

Received May 21, 2014; Accepted June 25, 2014; Published July 07, 2014

Citation: Johnbull OS, Uche AP, Kesiena AJ, Francis FA, Oyemocho A, et al. (2014) Prevalence and Risk Factors of Malaria in HIV-Infected Pregnant Women on Anti-Retroviral Therapy in Enugu, South East Nigeria. J AIDS Clin Res 5: 321 doi:10.4172/2155-6113.1000321

Copyright: (c) 2014 Johnbull OS, et al. This is an open-access article distributed under the terms of the Creative Commons Attribution License, which permits unrestricted use, distribution, and reproduction in any medium, provided the original author and source are credited. 
of the estimated total population of 130 million people, 489,000 severe malaria cases were reported, resulting in 200,000 deaths $[2,11,12]$. Nigeria is one of the countries in sub-Saharan Africa with a high HIV/ AIDS burden: in adults aged 15-49 years, a HIV prevalence rate of $4.4 \%$ (range 2.3-5.6\%) is estimated and the estimated total number of women aged 15years and older living with HIV is 1.6 million [13].

The aim of this study was to determine the prevalence of malaria parasitaemia among HIV-infected pregnant women on ART in Enugu, southeast Nigeria which will serve as a baseline data on the relationship between malaria and HIV infections in this region.

\section{Material and Methods}

\section{Study area}

Enugu State is an inland State in South East Nigeria with a capital at Enugu. It shares boundaries with Anambrato the West, Abia State to the South, Kogi to the North and Benue to the North East and Ebonyito the East. It is also known as the Coal City State of Nigeria. In the 2006 Population and Housing Census, Enugu state was made up of 1,596,042 males and 1,671,795 females [14]. Enugu Statehas rich agricultural land as a result of its location within the tropical forest and savannah belts. The humid climate and the distribution of rains almost all year round allow the breeding of mosquitoes throughout the year.

\section{Study design}

A cross sectional descriptive study design was used for the study.

\section{Study population}

Three hundred and one (301) confirmed HIV positive pregnant women in various trimesters who visited the antenatal clinic of the University of Nigeria Teaching Hospital (UNTH) Enugu, Nigeria were recruited for the study. Essentially, the Prevention of Mother-To-Child Transmission of HIV (PMTCT) clients were recruited through the routine HIV testing at the antenatal care (ANC) opt-out approach. Women who were sick and previously knew their HIV positive serostatus present by self-referral. About a third of the recruited PMTCT clients were referred from other public and private hospitals.

\section{Sample size and sampling techniques}

The sample size for the study was calculated by the standard methods. Considering the prevalence of malaria (23.7\%) in pregnant women [15], an error margin of $5 \%$ and a power of $80 \%$, a sample size of 278 was obtained. Taking into account a drop-out rate of $10 \%$, a total of 305 pregnant women were recruited for the study.

Non-probability sampling technique was used. All pregnant women received the modified group pre-test counselling before HIV testing, and individual post-test counselling when the test result was ready. During the post-test session, each patient was told her test result and offered additional counselling. If the rapid test result was reactive, she also underwent the "Western Blot" test for confirmation of the result. Those who were confirmed sero-positive were formally recruited into the PMTCT programme following their signing of the PMTCT consent forms. Once recruited, they were assigned a unique PMTCT number. Some HIV positive pregnant women who have been on adult ART programme or might have been referred from other PMTCT programmes did not undergo further testing but they were offered on-going counselling and enrolled into the PMTCT program. Also, confirmation of HIV infection and pregnancy were based on the hospital's protocols. All the subjects were on ART or ARV prophylaxis in accordance with the Nigerian National Prevention of Mother-ToChild Prevention of HIV (PMTCT) guidelines [16].

\section{Data collection}

The study was conducted between March and June, 2012. Consecutive eligible respondents seen over the study period were solicited to participate. Consenting subjects were counselled and their informed consent was duly obtained. Their socio-demographic characteristics (age, education, and occupation) as well as current CD4 counts, viral load, parity, antiretroviral duration were obtained from their clinic records while gestational age, body temperature, Intermittent Preventive Treatment (IPT), fever in the past weeks, drugs taken for treatment of fever and cotrimoxazole intake were obtained by direct interview.A finger prick was performed for the preparation of a blood film and for haemoglobin estimation. To ensure confidentiality, samples were labelled with coded numbers.

\section{Laboratory analysis}

Microscopic examination of stained slides: Thin blood films were fixed with methanol and all films (thick and thin) were stained with $10 \%$ Giemsa at pH 7.2 for $30 \mathrm{~min}$ as recommended by WHO [17]. Taking the number of leucocytes per micro litre of blood as 8,000 , parasite density of blood using the thick film was expressed as: parasite count (x) 8,000 divided by number of white blood cells (WBCs) counted. Stained slides were examined under the light microscope using x100 objective lens (with immersion oil) [18]. In the thin film, distinction was made to identify the different malarial species. Slides were examined and double checked by two experienced medical laboratory scientists/technicians and if there were differences, an additional assessment was made by another scientist and the average of two agreeing counts was recorded taking into consideration leukocytopenia.

Haemoglobin determination: The packed cell volume was determined by using recommended standard method $[19,20]$.

CD4 cell counts and viral loads: CD4 cell counts were measured by FACS Count (Becton Dickson, Mountain View, California) at each sampling point after incubation at room temperature based on the manual's information obtained from the hospital's laboratory.

The viral load of each sample was determined by the Versant HIV RNA 3.0 Assay (bDNA, Siemens, IL) as recommended by the manufacturer based on the manual's information obtained from the hospital's laboratory.

\section{Statistical analysis}

Data was analyzed using the STATA 10 software (Stata Corporation, College Station, Texas) statistical analysis package. A descriptive analysis was performed on each variable and bi-variate analysis to assess relationships between the variables: independent student t-test was used to assess significant mean difference of haemoglobin seen in malaria infestation; one-way ANOVA analysis was used to compare the level of anaemia and malaria density seen in the three trimesters of pregnancy. Chi square $(\chi 2)$ was used to compare relationships between categorical variables. Associations and differences were considered statistically significant if $\mathrm{p}$-value is less than 0.05 . Anaemia in pregnancy was defined as haemoglobin concentrations less than $10 \mathrm{~g} / \mathrm{dl}[3,21]$.

\section{Ethical considerations}

Ethical approval for the baseline study was obtained from the ethical committee of the PERFAR, University of Nigeria Teaching Hospital (UNTH) Enugu, Nigeria. 


\section{Results}

\section{Socio-demographic characteristics}

A total of $301 \mathrm{HIV}$ positive pregnant women (response rate 98.7\%) out of 305 that were recruited participated in the study. HIV-positive pregnant women in their first and second/third trimesters were $46.12 \%$ and $53.82 \%$, respectively, and their mean weight was $63 \mathrm{~kg}( \pm 14.0)$. The average age was 30years $( \pm 4.7)$ (Tables 1 and 2). Most of them were married (73.09\%) and the majority were rural dwellers (61.13\%). Each of them had at least three children (45.51\%). The two most frequently reported occupations were trading $(38.54 \%)$ and full time housewife (31.90\%).Those with secondary education were in the majority (53.16\%) (Tables 1 and 2).

\section{Prevalence of malaria}

About half (49.83\%)of the study population, had Plasmodium falciparum positive slides at the time of recruitment; over one third

\begin{tabular}{|c|c|c|c|}
\hline Variable & $\%(n)$ & $\underline{\text { Variable }}$ & $\%(n)$ \\
\hline Age (years) & & $\begin{array}{l}\text { Baseline CD4( cells/mm3 } \\
\text { blood) }\end{array}$ & \\
\hline$<25$ & $16.61(50)$ & $<200$ & $13.95(42)$ \\
\hline $26-30$ & $32.89(99)$ & $200-350$ & $36.88(111)$ \\
\hline \multirow[t]{2}{*}{$>30$} & $50.50(152)$ & $>350$ & $49.17(148)$ \\
\hline & & Median baseline CD4 (IQR) & $\begin{array}{l}350(236- \\
464)\end{array}$ \\
\hline Location & & Trimesters & \\
\hline Urban & $38.87(117)$ & $0-24$ weeks $\left(1^{\text {st }}\right)$ & $46.18(139)$ \\
\hline Rural & $61.13(184)$ & $>24$ weeks $\left(2^{\text {nd }}\right)$ & $53.82(162)$ \\
\hline Parity & & ART Type & \\
\hline Nullipara & $17.61(53)$ & Prophylaxis & $27.24(82)$ \\
\hline Primipara & $36.88(111)$ & Therapy & $72.76(219)$ \\
\hline \multirow[t]{2}{*}{ Multipara } & $45.51(137)$ & & \\
\hline & & ART Duration & \\
\hline Marital Status & & 12 months & $28.90(87)$ \\
\hline Married & $73.09(220)$ & $13-24$ months & 22.92(69) \\
\hline Single & $12.29(37)$ & 25 months and above & $48.17(145)$ \\
\hline Widow & $9.97(30)$ & Median Duration on ART (IQR) & $24(12-48)$ \\
\hline \multirow[t]{2}{*}{ Divorced } & $4.65(14)$ & & \\
\hline & & Malaria Parasite in Blood & \\
\hline Educational Level & & No Parasite & $50.17(151)$ \\
\hline No School & $2.99(9)$ & Parasite & $49.83(150)$ \\
\hline Primary & $13.95(42)$ & & \\
\hline Secondary & $53.16(160)$ & Reported fever & \\
\hline Tertiary & $29.24(88)$ & Yes & $34.22(103)$ \\
\hline Quranic(Islamic school) & $0.66(2)$ & No & $65.78(198)$ \\
\hline Occupation & & Cotrimoxazole & \\
\hline Farming & $6.31(19)$ & Yes & $7.64(23)$ \\
\hline Trading & $38.54(116)$ & No & $92.36(278)$ \\
\hline Artisan & $12.62(38)$ & & \\
\hline Housewife not working & $30.90(93)$ & $\begin{array}{c}\text { Intermittent Preventive } \\
\text { Treatment }\end{array}$ & \\
\hline Civil Servants & $8.97(27)$ & Yes & $34.88(105)$ \\
\hline Students & $2.66(8)$ & No & $65.12(196)$ \\
\hline
\end{tabular}

Table 1: Baseline socio - demographic characteristics of study population. reported having fever (Table 1) and one quarter of the women examined had a temperature $\geq 37.5^{\circ} \mathrm{C}$. A significantly higher proportion of women with body temperatures $\geq 37.5^{\circ} \mathrm{C}$ had detectable malaria parasitaemia compared with $36.8 \%$ with negative slides. Anaemia was significantly

\begin{tabular}{|l|c|c|c|c|}
\hline Variable & Mean & SD & Range & Median (IQR) \\
\hline Age (years) & 30.1 & 4.7 & $18-38$ & $31(28.0-34.0)$ \\
\hline Viral Load $(/ \mathrm{ml}$ blood) & 17968.0 & 71993.01 & $0-461720$ & $0(0-800)$ \\
\hline Body Temperature $\left({ }^{\circ} \mathrm{C}\right)$ & 37.0 & 3.0 & $33-83$ & $36.7(36.3-37.5)$ \\
\hline Pf parasite density $(/ \mu l$ blood) & 1302.9 & 1860.8 & $0-6200$ & $0(0-2400)$ \\
\hline Weight $(\mathrm{kg})$ & 63.4 & 14.0 & $36.6-97$ & $61(57.5-71.5)$ \\
\hline ART treatment duration (months) & 30.8 & 22.7 & $1-96$ & $24(12-48)$ \\
\hline Hemoglobin Level (g/dl) & 10.0 & 1.0 & $6.6-12.7$ & $10(9.5-10.2)$ \\
\hline
\end{tabular}

Table 2: Summary Statistics of Selected characteristics of Respondents.

\begin{tabular}{|c|c|c|c|}
\hline & $\begin{array}{c}\text { Respondent } \\
\text { has } \\
\text { Parasitaemia }\end{array}$ & $\begin{array}{c}\text { Respondent } \\
\text { has no } \\
\text { Parasitaemia }\end{array}$ & $\begin{array}{c}\text { P-Value of } \\
\text { Chi-square } \\
\left(X^{2}\right) \text { Test }\end{array}$ \\
\hline \multicolumn{4}{|l|}{ Age(years) } \\
\hline$<25$ & $58.00(29)$ & $42.00(21)$ & 0.378 \\
\hline $26-30$ & $50.51(50)$ & $49.49(49)$ & \\
\hline$>30$ & $46.71(71)$ & $53.29(81)$ & \\
\hline \multicolumn{4}{|l|}{ Location } \\
\hline Urban & $37.61(44)$ & $62.39(73)$ & 0.001 \\
\hline Rural & $57.61(106)$ & $42.39(78)$ & \\
\hline \multicolumn{4}{|l|}{ Reported fever } \\
\hline Presence of Fever & $74.76(77)$ & $25.24(26)$ & 0.000 \\
\hline Absence of Fever & $36.87(73)$ & $63.13(125)$ & \\
\hline \multicolumn{4}{|c|}{ Body Temperature $\left({ }^{\circ} \mathrm{C}\right)$} \\
\hline Normal & $45.73(107)$ & $54.27(127)$ & 0.008 \\
\hline High & $64.18(43)$ & $35.82(24)$ & \\
\hline \multicolumn{4}{|l|}{ Type of ART } \\
\hline Prophylaxis & $41.46(34)$ & $58.54(48)$ & 0.076 \\
\hline Therapy & $52.97(116)$ & $47.03(103)$ & \\
\hline \multicolumn{4}{|l|}{$\mathrm{IPT}^{*}$} \\
\hline Yes & $64.76(68)$ & $35.24(37)$ & 0.000 \\
\hline No & $41.84(82)$ & $58.16(114)$ & \\
\hline \multicolumn{4}{|c|}{ Anti-malaria Drug Before Coming } \\
\hline Yes & $31.65(50)$ & $68.35(108)$ & 0.000 \\
\hline No & $69.93(100)$ & $30.07(43)$ & \\
\hline \multicolumn{4}{|c|}{ Haemoglobin Level(g/dl) } \\
\hline Anaemia & $76.35(113)$ & $23.65(35)$ & 0.000 \\
\hline Normal & $24.18(37)$ & $75.82(116)$ & \\
\hline \multicolumn{4}{|c|}{ CD4 Level(/ml blood) } \\
\hline$<200$ & $59.52(25)$ & $40.48(17)$ & 0.070 \\
\hline $200-250$ & $54.95(61)$ & $45.05(50)$ & \\
\hline$>350$ & $43.24(64)$ & $58.76(84)$ & \\
\hline \multicolumn{4}{|l|}{ Parity } \\
\hline Nullipara & $47.17(25)$ & $52.83(28)$ & 0.807 \\
\hline Primipara & $48.65(54)$ & $51.35(57)$ & \\
\hline Multipara & $51.82(71)$ & $48.18(66)$ & \\
\hline
\end{tabular}

ART- anti-retroviral therapy; ITP- Intermittent preventive treatment.

Table 3: Distribution of detectable parasitaemia in pregnant women with HIVIAIDS. 
associated with the presence of malaria parasites as $76.35 \%$ of pregnant women who havepositive slides have haemoglobin levels $<10 \mathrm{~g} / \mathrm{dl}$. Likewise, more pregnant women who reported having fever $(74.76 \%)$ had malaria parasites. Furthermore, more of those who were on ART therapy (52.97\%) had malaria parasites (Table 3). A higher proportion of pregnant women whose CD4 was above 350 cells $/ \mathrm{mm}^{3}$ had negative parasitaemia. Also, more of those who were multiparous presented with malaria parasites.

Only $35.24 \%$ of pregnant women were on intermittent preventive treatment(IPT) for malaria prevention and $8.0 \%$ had taken cotrimoxazole therapy. One third of women reported taking an antimalarial drug on self-medication within 2-5 days before going to the hospital. Seventythree percent were on antiretroviral therapy compared with $27.0 \%$ on antiretroviral prophylactic therapy. The median duration of ART was 24 months (IQR [12-48 months]) (Table 2). About half the population (49.17\%) had CD4 counts $>350$. The median viral load was zero (IQR [0-800]), while $49.0 \%$ of pregnant women had haemoglobin less than $10 \mathrm{~g} / \mathrm{dl}$, the mean haemoglobin concentration was $1.0 \mathrm{~g} / \mathrm{dl}$.

\section{Risk factors associated with malaria infection}

A number of risk factors were associated with malaria infection in pregnancy (Table 4). Age was an important risk factor; women aged 26-30years and >30years had reduced odds of having malaria by $18 \%$ and $6 \%$, respectively. The odds of having malaria infection doubled when moving from urban to rural settlements (AOR 2.04, CI [1.07-3.91] $\mathrm{P}<0.001)$. Likewise, a high body temperature $\left(>37.5^{\circ} \mathrm{C}\right)$ significantly increased the odds of having malaria infection by $90 \%$ (AOR 1.90, CI [0.94-3.86] $\mathrm{P}<0.001)$. Pregnant women on ART therapy hadan increased odds ratio of having malaria parasites (AOR 2.33 CI [1.065.10] $\mathrm{P}<0.05)$. Those whose CD4 count was $200-350$ and $>350$ had reduced odds ratio of malaria parasitaemia (AOR 0.50, CI [0.18-1.44] $\mathrm{P}=0.202$ ) and (AOR 0.65, CI [0.24-1.73] $\mathrm{P}=0.391$ ) (Table 1). Malaria parasites were unlikely to be seen in those with normal haemoglobin levels (>10 g/dl) (AOR 0.08 CI [0.04-0.16] P<0.001). Pregnant women who had not recently been treated for an acute malaria attack were about nine times more likely to have presence of malaria parasites in blood than those treated recently (AOR 9.30, CI [4.44-19.50] $\mathrm{P}<0.001$ ). Illiteracy or no education was a contributory factor as this group had the highest mean malaria density $(>3000$ parasites $/ \mu \mathrm{L})$. Among all the socio-demographic variables considered only educational levels were significant different $(\mathrm{F}=7.007 \mathrm{p}<0.0001)$ with respect to malaria density (Figure 1).

\begin{tabular}{|c|c|c|c|c|c|}
\hline Variable & $\%(n)$ & Unadjusted OR(95\% Cl) & P-value & Adjusted OR(95\% Cl) & P-value \\
\hline \multicolumn{6}{|l|}{ Age (years) } \\
\hline$<25$ & $16.61(50)$ & & & & \\
\hline $26-30$ & 32.89(99) & $0.73(0.37-1.47)$ & 0.387 & $0.82(0.29-2.36)$ & 0.722 \\
\hline$>30$ & $50.50(152)$ & $0.63(0.33-1.21)$ & 0.168 & $0.94(0.34-2.61)$ & 0.900 \\
\hline \multicolumn{6}{|l|}{ Location } \\
\hline Urban & $38.87(117)$ & & & & \\
\hline Rural & $61.13(184)$ & $2.25(1.40-3.62)$ & 0.001 & $2.04(1.07-3.91)$ & 0.031 \\
\hline \multicolumn{6}{|c|}{ Body Temperature $\left({ }^{\circ} \mathrm{C}\right)$} \\
\hline Normal & $77.74(234)$ & & & & \\
\hline High & $22.26(67)$ & $2.12(1.21-3.73)$ & 0.009 & $1.90(0.94-3.86)$ & 0.075 \\
\hline \multicolumn{6}{|l|}{ ART Type } \\
\hline Prophylaxis & $27.24(82)$ & & & & \\
\hline Therapy & $72.76(219)$ & $1.59(0.95-2.66)$ & 0.077 & $2.33(1.06-5.10)$ & 0.035 \\
\hline \multicolumn{6}{|c|}{ CD4 count (/ml blood) } \\
\hline$<200$ & $13.95(42)$ & & & & \\
\hline $200-350$ & $36.88(111)$ & $0.82(0.40-1.71)$ & 0.611 & $0.50(0.18-1.44)$ & 0.202 \\
\hline$>350$ & $49.17(148)$ & $0.52(0.25-1.04)$ & 0.064 & $0.65(0.24-1.73)$ & 0.391 \\
\hline \multicolumn{6}{|l|}{ IPT } \\
\hline Yes & $34.88(105)$ & & & & \\
\hline No & $65.12(196)$ & $0.39(0.24-0.64)$ & 0.000 & $0.38(0.18-0.77)$ & 0.008 \\
\hline \multicolumn{6}{|c|}{ Anti malarial drug taken before coming to hospital } \\
\hline Yes & $52.49(158)$ & & & & \\
\hline No & $47.51(143)$ & $5.02(3.08-8.20)$ & 0.000 & $8.31(4.31-16.00)$ & 0.000 \\
\hline \multicolumn{6}{|c|}{ Haemoglobin level (g/dl) } \\
\hline Anaemia & $49.17(148)$ & & & & \\
\hline Normal & $50.83(153)$ & $0.10(0.06-0.17)$ & 0.000 & $0.08(0.04-0.17)$ & 0.000 \\
\hline
\end{tabular}

Table 4: Logistic regression for factors associated with malaria parasite in HIV pregnant women. 


\section{Discussion}

In this study, a high maternal malaria prevalence rate $(49.83 \%)$ was found among HIV-infected pregnant women during their ANC visit. This rate is close to reports from similar studies in Ekpoma, Nigeria (53\%) [22] and Malawi (56\%) [23], but higher than $21 \%$ reported amongst pregnant women in Jos, Nigeria [24]. The prevalence of $P$. falciparum malaria in these HIV-infected pregnant women is a reflection of the high prevalence of this species of malaria in the Nigerian population because over $98 \%$ of malaria infection is caused by this species. Also in the study, no other type of species was detected except P.falciparum.

A number of risk factors were found to be associated with malaria infection. Women above 30 years of age had a higher risk of infection (AOR 0.94, CI $(0.34-2.61) \mathrm{P}=0.900$. Age is a co-factor in disease progression, and the immunity to malaria and HIV infection has been shown to be age-dependent $[25,26]$. It is possible that older HIV-infected individuals may be more prone to developing infections including malaria than the younger HIV-infected individuals. This association needs to be verified in subsequent studies. Living in rural areas was also identified as a risk factor. The significantly higher parasitaemia found among the rural dwellers can be explained from the fact that they are more exposed to mosquito bites, due to thick vegetations and poorer drainage systems which encourage mosquito breeding in stagnant water around their homes. More so, they are less likely to use insecticide treated nets than the urban dwellers though not investigated in our study. The higher proportion of HIV and malaria co-infection among the rural dwellers (61\%) suggests that rural communities now bear the greater burden of HIV/AIDS [27], thus overstretching rural health systems.

HIV-positive infected pregnant women require special attention and follow-up to reduce the risk of maternal death and adverse pregnancy outcomes resulting from the effects of anemia, especially among these special populations of HIV-infected women. Infection with $P$. falciparum was strongly associated with anaemia in $75 \%$ of cases, which is consistent with findings from other studies of pregnant women [28]. In practice, most hospitals in Nigeria use a lower level of haemoglobin $(<10 \mathrm{~g} / \mathrm{dl})$ as an indication of anaemia. This is justified on the basis of work of Lawsonet al, which showed that serious harm to the mother and foetus did not occur until the haemoglobin value was below $10 \mathrm{~g} / \mathrm{dl}$ [29]. The risk of anaemia secondary to malaria could be reduced through prompt and effective treatment during pregnancy to optimize the chances of an HIV-infected pregnant woman delivering a healthy infant. In a review of studies of Plasmodium falciparum-related anaemia in pregnant women, it was suggested that up to 400,000 pregnant women develop moderate or severe anaemia (hemoglobin level $<8.0 \mathrm{~g} / \mathrm{dL}$ or haematocrit $<25 \%$ ) each year in sub-Saharan Africa as a result of malaria infection [30]. The HIV-associated risk of malaria affects all parities and is consistently higher in multiparous women, as observed in the study presented here.In turn, this increases the risk of still birth, preterm delivery, low birth and fetal growth restriction which agrees with some studies from Uganda $[12,30]$. The odds ratio or relative risk of parasitaemia and risk of malarial fever increase with decreasing CD4 count and increasing viral load. But usually, ART treatment could increase CD4 counts and decrease viral load but in our study, it is not like this which may be due to non-adherence of ART drugs.

Prophylactic treatment with IPT is an important approach to reduce the burden of malaria in pregnancy. Despite recommendation by the World Health Organization of at least three prophylactic doses of IPT during the second and third trimesters of pregnancy for HIV-infected pregnant women to prevent malaria [31], 65\% of the subjects studied in all trimesters had never taken IPT. This might increase the severity of the consequences of malaria without intervention, which may lead to transmission of infections to the fetus during the intrauterine and intra-partum periods. Many of the HIV-infected pregnant women with malaria never had any knowledge of IPT and this may be due to lack of personal and institutional updates on new interventions in preventing malaria during pregnancy in the country. It may also be as a result of a lack of budgetary support in making available copies of the national IPT guidelines and strategic documents available within health facilities.In our study, it is important to note that those women who were not on IPT had a significantly reduced odds ratio for malaria parasitaemia (AOR 0.38, CI [0.18-0.77] $\mathrm{P}<0.01$ ).

Prophylaxis with cotrimoxazole is also reported to be beneficial in malaria endemic areas [32]. However, $92.36 \%$ of the HIV-infected pregnant women in this study were not on cotrimoxazole. The expanded use of cotrimoxazole as a prophylactic agent in HIV-infected people might have an added benefit of malaria prevention, the efficacy of cotrimoxazole for malaria prevention is not yet known among these special groups (HIV-infected pregnant women).

\section{Conclusion}

Despite the high prevalence of malaria and HIV in many parts of the tropics, knowledge of how these two important diseases interact is still hampered by lack of knowledge in many key areas. Public health policies aimed at increasing hemoglobin levels should continue to support programs, particularly in rural areas, that provide iron supplementation, appropriate antiretroviral regimens to HIV-infected women and a system to support provision of insecticide treated bed nets (ITNs) \& intermittent preventive antimalarial treatment during pregnancy according to the newly adopted national policy. Also, as more countries adopt policies of antiretroviral and antimalarial interventions in pregnancy, the interrelationship and ultimate benefit of these two interventions requires continued evaluation. The observed increased level of malaria parasites with IPT is surprising and requires further investigation.

\section{Limitations of the Study}

One of the greatest limitations was not being able to do follow-up to check the adherence of their ART medication and also to know why there was increased level of parasitaemia in patients on IPT.

\section{Acknowledgement}

We thank Prof Stephanie K. Yanow, Alberta Health Services, Canada for critical reading of the manuscript. We sincerely want to thank all other people who were available and provided advices during the study and also thank Chizoba Ezeagu for assistance with data arrangement

\section{References}

1. Focà E, Odolini S, Brianese N, Carosi G (2012) Malaria and HIV in adults: when the parasite runs into the virus. Mediterr J Hematol Infect Dis 4: e2012032.

\section{WHO (2011) World malaria report.}

3. Steketee RW, Nahlen BL, Parise ME, Menendez C (2001) The burden of malaria in pregnancy in malaria-endemic areas. Am J Trop Med Hyg 64: 28-35.

4. WHO (2004) Malaria and HIVIAIDS interactions and their implications for public health policy. Report of a technical consultation. 23-25 June 2004. Geneva, World Health Organization.

5. World Health Organization (WHO) (2003) The African Malaria Report 2003 WHO, Geneva, Switzerland.

6. Huff B (2000) HIV and Malaria: two intertwining epidemics. Am Found AIDS Res 6: 1-5.

7. Kublin JG, Patnaik P, Jere CS, Miller WC, Hoffman IF, et al. (2005) Effect of 
Citation: Johnbull OS, Uche AP, Kesiena AJ, Francis FA, Oyemocho A, et al. (2014) Prevalence and Risk Factors of Malaria in HIV-Infected Pregnant Women on Anti-Retroviral Therapy in Enugu, South East Nigeria. J AIDS Clin Res 5: 321. doi:10.4172/2155-6113.1000321

Plasmodium falciparum malaria on concentration of HIV-1-RNA in the blood of adults in rural Malawi: a prospective cohort study. Lancet 365: 233-240.

8. Rana FS, Hawken MP, Mwachari C, Bhatt SM, Abdullah F, et al. (2000) Autopsy study of HIV-1-positive and HIV-1-negative adult medical patients in Nairobi, Kenya. J Acquir Immune Defic Syndr 24: 23-29.

9. Holmes CB, Losina E, Walensky RP, Yazdanpanah Y, Freedberg KA (2003) Review of human immunodeficiency virus type 1-related opportunistic infections in sub-Saharan Africa. Clin Infect Dis 36: 652-662.

10. ter Kuile FO, Parise ME, Verhoeff FH, Udhayakumar V, Newman RD, et al. (2004) The burden of co-infection with human immunodeficiency virus type 1 and malaria in pregnant women in sub-saharan Africa. Am J Trop Med Hyg 71: $41-54$.

11. Onyenekwe CC, Meludu SC, Dioka CE, Salimonu LS (2002) Prevalence of asymptomatic malaria parasitaemia amongst pregnant women. Indian J Malariol 39: 60-65

12. Abu-Raddad LJ, Patnaik P, Kublin JG (2006) Dual infection with HIV and malaria fuels the spread of both diseases in sub-Saharan Africa. Science 314 1603-1606.

13. UNAIDS (2008) Country Situation Analysis: HIV and AIDS estimates.

14. National Population Commission, Abuja 2010.

15. World Medical Association Declaration of Helsinki (2000) Ethical principles for medical research involving human subjects. World Medical Association.

16. (2005) Federal Ministry of Health National Guidelines and Strategies for Prevention and Control of Malaria during Pregnancy. Abuja, Federal Government of Nigeria.

17. Federal Ministry of Health (2010) Nigeria National Prevention of Mother-ToChild Prevention of HIV (PMTCT) PMTCT guidelines.

18. WHO (2004) A strategic framework for malaria prevention and control during pregnancy in the African region. WHO Regional Office for Africa, Brazzaville, Republic of Congo. AFR/MA/04/01.

19. World Health Organisation (WHO) (1992) The prevalence of Anaemia in women. A tabulation of available information. Geneva. Switzerland, WHO.

20. Amadi AN, NjokuOO, Onwere S, Kamanu Cl, Aluka C (1999) Study on the association between maternal malaria infection and anaemia. Journal of Medical Investigation and Practice 1: 17-21.

21. Agwu E, Ihongbe JC, Okogun GR, Inyang NJ (2009) High incidence of co- infection with Malaria and Typhoid in febrile HIV infected and AIDS patients in Ekpoma, Edo State, Nigeria. Braz J Microbiol 40: 329-332.

22. Verhoeff FH, Brabin BJ, Hart CA, Chimsuku L, Kazembe P, et al. (1999) Increased prevalence of malaria in HIV-infected pregnant women and it's implication for malaria control. Trop Med Int Health 4: 5-12.

23. Uneke CJ, Ogbu O, Inyama PU, Anyanwu GI (2005) Malaria infection in HIVseropositive and HIV-seronegative individuals in Jos-Nigeria. J Vector Borne Dis 42: $151-154$

24. Steketee RW, Wirima JJ, Bloland PB, Chilima B, Mermin JH, et al. (1996) Impairment of a pregnant woman's acquired ability to limit Plasmodium falciparum by infection with human immunodeficiency virus type-1. Am J Trop Med Hyg 55: 42-49.

25. Schwartz E, Sadetzki S, Murad H, Raveh D (2001) Age as a risk factor for severe Plasmodium falciparum malaria in nonimmune patients. Clin Infect Dis 33: $1774-1777$.

26. Wabwire-Mangen F, Shiff CJ, Vlahov D, Kline R, Serwadda D, et al. (1989) Immunological effects of HIV-1 infection on the humoral response to malaria in an African population. Am J Trop Med Hyg 41: 504-511.

27. Ogboi Sonny Johnbull (2003) Advocating rural community care and support in HIVIAIDS management in Nigeria. Mera Africa Health. November 26: 9-10.

28. Lawson JB, Stewart DB (1969) Obstetrics and Gynaecology in the Tropics and Developing countries. Edward Arnold Publisher 73.

29. Briand V, Badaut C, Cot M (2009) Placental malaria, maternal HIV infection and infant morbidity. Ann Trop Paediatr 29: 71-83.

30. Wabwire-Mangen F, Shiff CJ, Vlahov D, Kline R, Serwadda D, et al. (1989) Immunological effects of HIV-1 infection on the humoral response to malaria in an African population. Am J Trop Med Hyg 41: 504-511.

31. Guyatt HL, Snow RW (2001) The epidemiology and burden of Plasmodium falciparum-related anemia among pregnant women in sub-Saharan Africa. Am J Trop Med Hyg 64: 36-44.

32. Muhangi L, Woodburn P, Omara M, Omoding N, Kizito D, et al. (2007) Associations between mild-to-moderate anaemia in pregnancy and helminth, malaria and HIV infection in Entebbe, Uganda. Trans R Soc Trop Med Hyg 101: 899-907.

33. Wabwire-Mangen F, Shiff CJ, Vlahov D, Kline R, Serwadda D, et al. (1989) Immunological effects of HIV-1 infection on the humoral response to malaria in an African population. Am J Trop Med Hyg 41: 504-511. 